\title{
Development of Self-Learning Program for the Bending Process of Quartz Glass
}

\author{
Masamichi Suda \\ Advanced Fibro-Science, \\ Kyoto Institute of Technology, \\ Kyoto, \\ Japan
}

\author{
Noriaki Kuwahara \\ Advanced Fibro-Science, \\ Educational Program Center, \\ Kyoto Institute of Technology, \\ Kyoto, Japan
}

\author{
Akio Hattori \\ Techno Eye Corporation, \\ Kyoto, \\ Japan
}

\author{
Akihiko Goto \\ Department of Information Systems \\ Engineering, \\ Faculty of Design Technology, \\ Osaka Sangyo University, \\ Osaka, Japan
}

\author{
Hiroyuki Hamada \\ Advanced Fibro-Science, \\ Future-Applied Conventional Technology Center, \\ Kyoto Institute of Technology, \\ Kyoto, Japan
}

\begin{abstract}
Quartz glass is a high-performance glass material with its high heat and chemical resistance, wide optical transparency ranging from ultraviolet light to infrared light, and the high formativeness as a glass material. Because it has high morphological stability due to its heat resistance and low thermal expansion, it is widely used as material for specialized research and development or high-precision components. There are several techniques to process quartz glass material, and an important process among them is the fire processing. The fire processing requires technology to heat and mold glass material in high temperature, and high-quality processing is done by the manual works of experts. In this study, we focused on bending work, which is the process that demands particularly high skill among the fire processing. We developed a self-learning program for beginners to improve their skill in short time by using the bending know-hows of the experts that were clarified through process analysis, product evaluation and an interview with the expert, and examined its effectiveness. As a result, a consistent educational effect was observed in the bending skill improvement of the beginner in a short period of time.
\end{abstract}

Keywords-Quartz glass; self-learning; bending; experts; beginner; process analysis; text analysis

\section{INTRODUCTION}

At the bending process, a technician holds the both ends of a quartz glass tube with his both hands while heating it with the flame of a burner with rotating the tube with his fingers. $\mathrm{He}$ bends the heated and softened tube to a predetermined angle, and this entire process is conducted manually. Fig. 1 shows the technician's posture during this process and the positions of the quartz glass tube and the burner. Bending work is an indispensable technique to produce a tube-shaped components for stably transporting fluids such as special chemicals and gases. Because of its heat resistance and small thermal expansion characteristics, high precision work is required when processing quartz glass products. Especially in case of bending a tube, smooth curve and inner surface are required as let the flow of chemical or gas transferred smoothly without disturbance, in addition to the dimensional accuracy. Only an expert who possesses high degree of skill can achieve such a high-quality bending work. However, the know-how required for improving beginners' bending technique is equivalent to the tacit knowledge that experts possess. And these tacit knowledge has not been converted into explicit knowledge that can be understood by beginners. Thus, when beginners start learning bending work, they repeat trial and error, therefore the learning period naturally becomes prolonged. For instance, in the example of a Japanese quartz glass product manufacturing company, it requires more than 20 years to for technicians to reach the same skill level as experts. And even among these experts, there are only a small number of technicians who are capable to produce a high-quality bending work. Therefore, if shortening of learning period is achieved, it is expected to have a significant effect on human resources development.

It is easy to use for technical learning in the current technology environment. We can use self-analysis by the video to help engineers learn to notice [1]. In the Kounin's study, the effect of self-analysis using video in teacher education programs has been reported [2]. In Nakahira's study, it is reported that technology improvement is effective by taking and viewing its own video [3].

Especially small business companies in japan are required to make effective use of limited human resources and time. There are many requests for self-learning programs such as elearning, and examples of learning programs using video have been reported [4].

Efforts on self-learning using e-learning in the field of nursing skills [5] suggested that viewing and exercising video influences student motivation and self-evaluation ability. In addition, the work of Downey, it has been reported that it was possible to see himself from a different point of view by looking at their own video [6]. 
In addition, it is suggested that the effectiveness of feeding back to the educators about the level of comprehension of the subjects of education [7]. However, in the case of teaching beginners directly from experts, grasping the problems and understanding levels of beginners is left to the individual's sense, so it is difficult to objectively evaluate them. Moreover, when experts pass on tacit knowledge, "recipients acquire their own interpretations and tips in accordance with their own system and give repeat accuracy" [8] due to lack of languageization of know-how and Ambiguity in expression. As a result, beginners take a long time to improve technology.

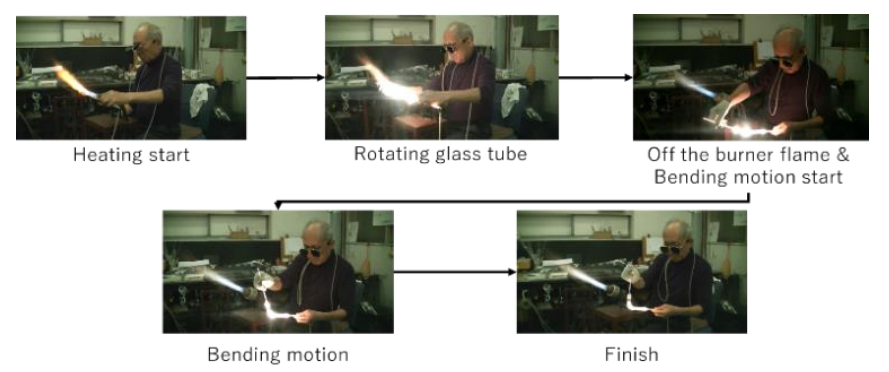

Fig. 1. Technician's posture during bending process and the positions of the quartz glass tube and the burner.

In this study, in order to analyze his know-how in bending work, an interview with an expert was conducted using a video that documented his process. In the field of fire processing of quartz glass, the number of previous study examples are very limited. Though there is one example, the study of Umemura et al., that analyzed the motion of the work to machine a glass tube while rotating it by fingers [9], there has no study on the process sequence of experts and the know-how that exists in that process regarding the fire processing of quartz glass. As a result of process analysis [10] and product evaluation conducted by Suda et al., it is clarified that the products made by the expert possess significant characteristics [11]. In this study, we engaged with the identification of the know-how of an expert through an interview with the expert using a video. Moreover, we developed a self-learning program for beginners based on the know-how obtained from the expert, and examined its effect on beginners.

In order to improve the bending skill of a beginner in a short period of time, it is considered necessary for beginners to notice the difference in skill between experts and beginners. In recent years, a skill improvement program that uses virtual reality (VR) is being examined. Takahashi et al. reports that: "Using the direct advantage of VR, it becomes possible to construct a system to numerically measure how closely the movement of a learner followed the example, displays it in real time and supplies feedback. This system enables to produce a training system and use it as an indicator to make sure the achievement of training level. This has an advantage, especially for beginners, of copying correct forms. Also in this case, it is desirable to develop a VR educational tool that listens to experienced trainers, learns from trainers a series of basic movements from the beginning to the final stage of movements, measures movements of beginners and gives feedbacks" [12]. Thus, also in bending work, the beginner comparatively examines the movements of the expert and himself by watching video, which provides him an opportunity to notice the difference in movements and to follow the expert's movement for improving his skill. Moreover, by adding the expert's information to the self-learning program, such as the intention of the expert and the effect of each step that are difficult for beginners to understand only by watching a video, it is expected to contribute to the skill improvement in the short time by acquiring the expert's know-how through this program.

In this study, we developed a new self-learning program and verified its effect, which is not direct teaching by experts on quartz glass fire processing. First, we interviewed an expert using process videos and process analysis, and worked on elucidating important expert know-how in bending processing. Next, I developed a self-learning program using video viewing and added expert know-how gained by interview. And we conducted experiments for a beginner. In order to measure the effect that the program brings to a beginner, it was evaluated compared to a non-expert who did not experience this program. We report on its learning effect.

\section{EXPERIMENTAL METHOD}

\section{A. Identification of the Know-How of the Expert by Interview}

We identified the know-how the expert uses at each step through an interview while watching a video of his bending work. The selected expert has 55 years of experience in bending work. In the previous study by Suda et al. clarified that bending work consists of two steps, namely a heating step and a bending step [2]. In the interview with the expert using the bending process video. The process is consisted of the following three steps: 1) the heating step; 2) transition from the heating step to the bending step; and 3) the bending step.

\section{B. Self-Learning Program}

In this program, we showed the beginner of two videos every time when he engaged in the bending process, one is the video recording his work movement during the bending process and the other is the example video of the expert. Moreover, the beginner answered a writing-type questionnaire on bending process after watching the videos, and then conducted the bending process. The questions in the questionnaire were thus: 1) "what were some of the specific differences in your processing work compared to the expert's?" 2) "what do you think are the points that the expert place emphasis on?"; and 3) "what do you think needs improvement in your work?" From the first to the fourth time when conducting the bending process, the know-how of the expert was not disclosed to the beginner, but from the fifth time to the eighth time, a diagram showing the know-how was disclosed to the beginner during the bending process. Fig. 2 shows the flow of the program. In this program, beginners try only video information from the first time to the fourth time. The aim is to improve the comprehension of know-how by disclosing knowhow of experts after beginners thought about themselves by trial and error. In addition, to update every time the beginner video in this program. It is possible for beginners themselves to learn while confirming growth. Furthermore, in this program, it is also one of the features that educators or managers can visualize progress and changes on beginners' thinking aspects by describing comments each time. 

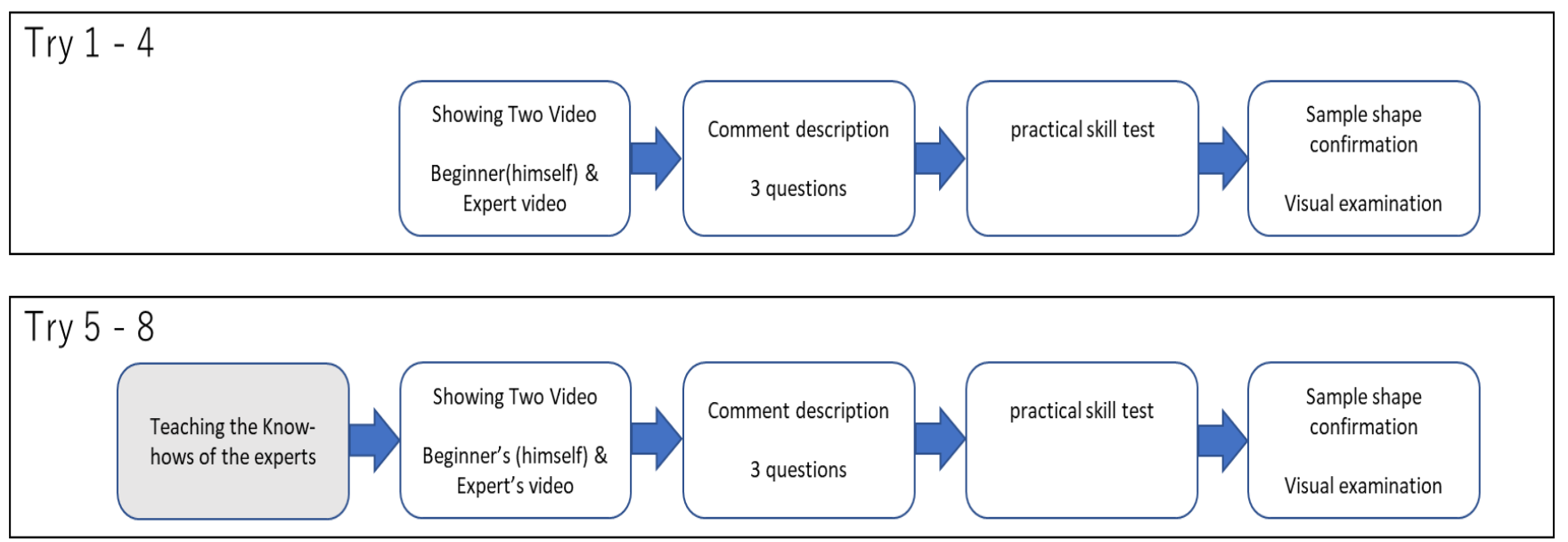

Fig. 2. Self-learning program of bending process.

\section{Process Analysis}

We assigned an expert (55 years of experience), a nonexpert (5 years of experience) and a beginner (half year of experience) as test subjects. Their bending works were recorded as digital videos, and time measurement of each step was conducted using these footages. The work of the expert and the non-expert were measured for three times each, and that of the beginner was measured for eight times in total using the self-learning program.

\section{Product Evaluation}

We assigned an expert (55 years of experience), a nonexpert ( 5 years of experience) and a beginner (half year of experience) as test subjects, asked them to conduct the bending work for comparing the external appearances of the bent parts on their finished products. Moreover, the outer diameter of the bent tube was measured by a digital vernier caliper, to examine the changes before and after bending process. The works of the expert and the non-expert were measured for three times each, and that of the beginner was measured for eight times in total using the self-learning program.

\section{E. Text Analysis of Writing-Type Questionnaire}

Counting the word numbers and the word classes included in the answers to the questionnaire written by the beginner for the self-learning program, we examined how his answer changed through eight times trials. For the text analysis, "KH Coder" which is a freeware for statistically analyzing text-type (sentences-type) data.

\section{RESULT}

\section{A. Inteview with the Expert}

As the result of the interview, the following know-hows were identified: 1) in the heating process, the expert set the heating range first, and then heat the part to be bent based on the curvature angle; 2) during the transition from heating to bending step, as the important point to be focused on during the heating, the expert checked the contraction status on the tube first, especially at the boundary between the heated area and non-heated area, then moved to bending work; 3) during the bending work, the expert conducted the bending motion at the angle that is easy to visually observe the expansion of the tube. Fig. 3 shows the whole process, and the timings where each know-how is employed.

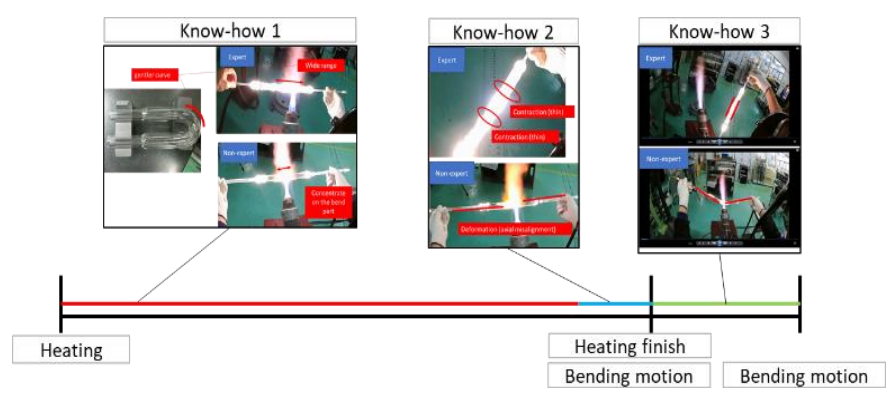

Fig. 3. The whole process and timings of the each know-hows.

\section{B. Process Analysis}

Fig. 4 shows the work time ratio between the heating step and the bending step. As can be seen from the video of the process, it was clarified that the ratio of bending work increased in the work of the non-expert compared to the expert or the beginner. Fig. 5 shows the transition in the total processing time of the beginner. In the first to the fourth time conducted before the beginner was informed of the know-how, the total processing time tended to increase. However, from the fifth and the subsequent trials after the know-how education, the processing time of the beginner tended to decrease.

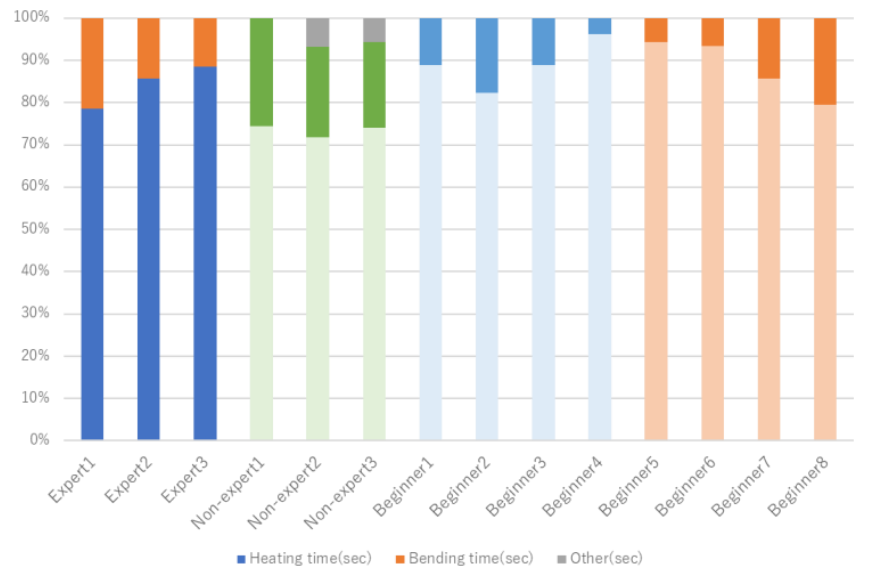

Fig. 4. Process time of heating \& bending step. 


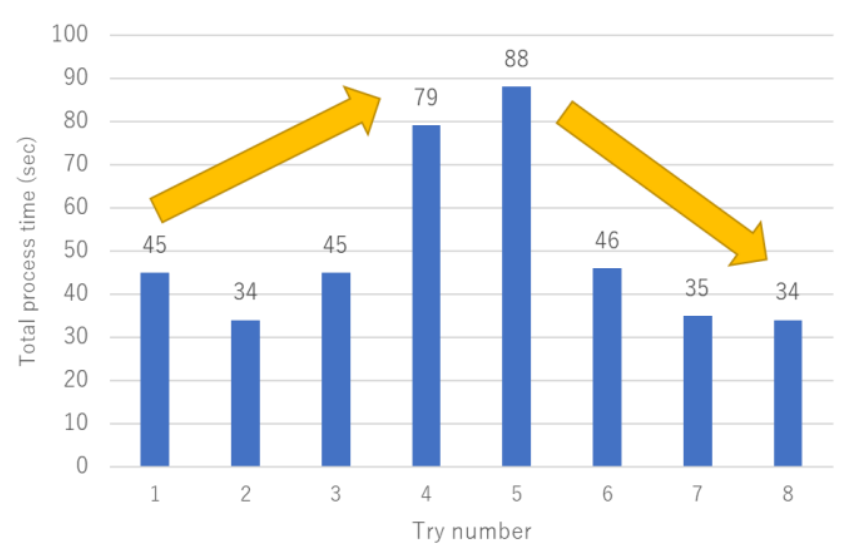

Fig. 5. The transition in the total processing time of the beginner.

\section{Product Evaluation}

Fig. 6 shows the picture of the bent part of each sample. Compared to the expert, the inside of the bent part done by the non-expert displayed a pleat-shaped deformation. The similar deformation can be seen in the products done by the beginner before the know-how education, but it cannot be seen in the samples produced by the beginner after the know-how education. Additionally, Fig. 7 shows the changes in the outer diameter of the bent parts. Though the beginner displayed a larger outer diameter change compared to the work done by the expert throughout the program, the change significantly decreased by the eighth time. Fig. 8 shows the correlation between the processing time and the outer diameter change. The non-expert, who did not take part in the self-learning program, showed a little change in the outer diameters, but his process time tends to increase. While the beginner, who took part in the self-learning program, displayed a tendency to shorten the processing time, even though there were large changes in the outer diameters by his seventh trial. But he finally approached to the result of the expert at the eighth trial.

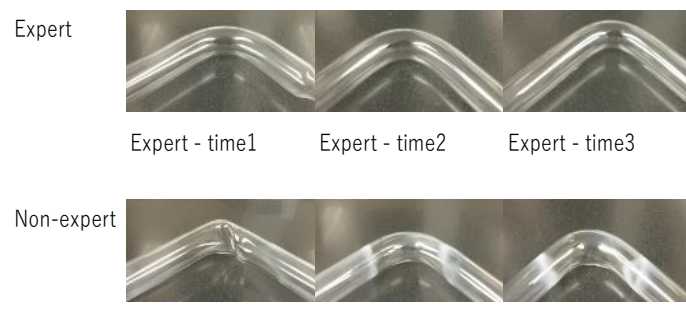

Non-expert-time1 Non-expert-time2 Non-expert-time3

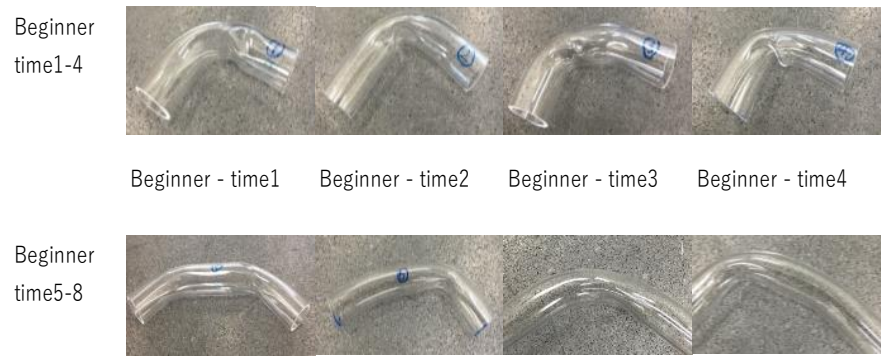

Beginner-time5 Beginner-time6 Beginner-time7 Beginner-time8

Fig. 6. The sample shapes of bent part.

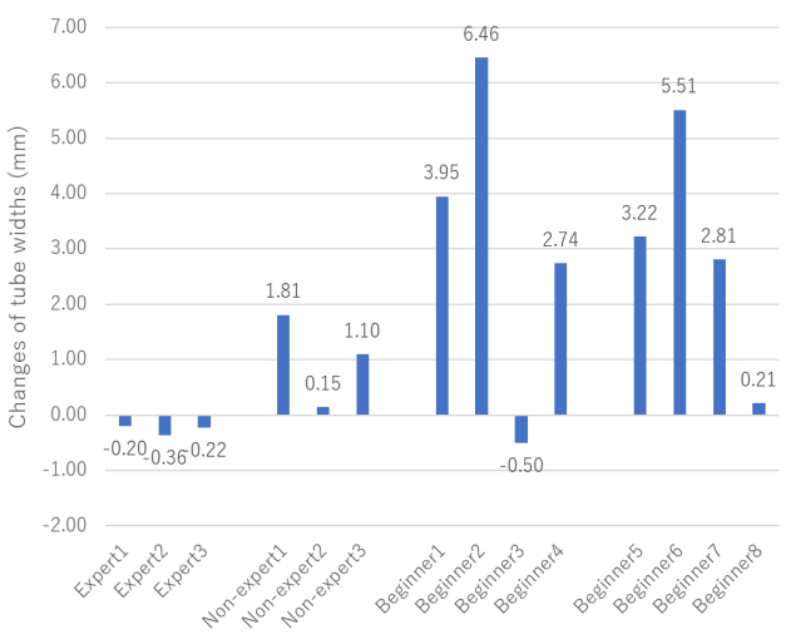

Fig. 7. The changes about the outer diameter of bent part.

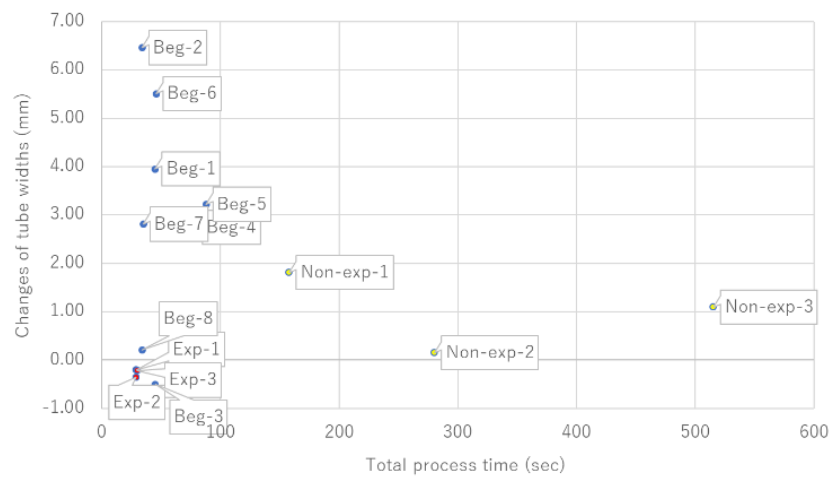

Fig. 8. The correlation between the processing time and the outer diameter change.

\section{Text Analysis of Writing-Type Questionnaire}

The text analysis of the questionnaire filled by the beginner during the self-learning program was conducted. The research result counting the total word number and the number of adjectives is shown in Fig. 9. The adjectives tended to increase from the fifth time through to the eighth time. Moreover, as can be seen in Fig. 10, words related to heating and to the glass joint called "ponte" were seen for the first time from the fifth to eighth trials, after the introduction of the know-how.

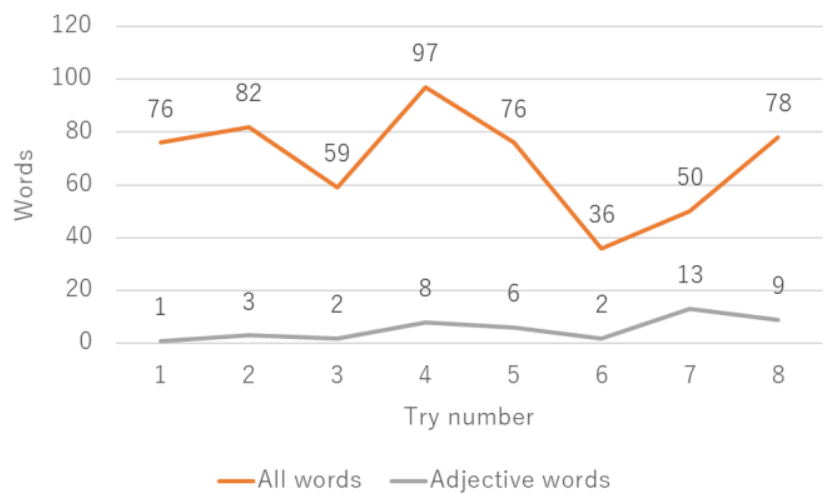

Fig. 9. The result counting the total word number and the number of adjectives. 


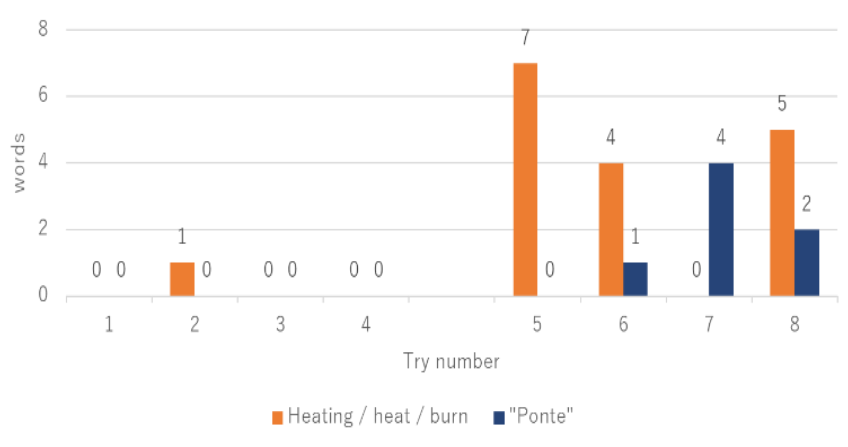

Fig. 10. Comparison of words related to heating and "Ponte".

\section{DisCUSSION}

As a result of comparing the beginner who underwent the self-learning program and the non-expert who has five years of experience, a clear difference in the total processing time required for the bending work was observed. It is considered that through comparatively watching and learning from the video of this learning program, the beginner noticed that the expert formed a bent part only by one bending motion, while he noticed his motions differed from the expert through the video. However, in the early stage of the experiment, the beginner merely mimicked the movement of the expert from the video and there was absolutely no improvement in the quality of the bent parts. On the other hand, because the nonexpert knew the difficulty of the bending technique that the expert employs, to complete the bending work through only one bending movement. Therefore the non-expert employed a method where he gradually bended the angle. Therefore, the forming of the bent part was better compared to that of the beginner done in the early stage, but it was inferior in the productivity due to the significant increase in the processing time.

Until the fourth time, the quality of the bent part by the beginner did not improve and it was almost entirely stagnated. During this time, there was no significant change in the comments the beginner wrote on the questionnaire and therefore it can be inferred that he could not find a solution or suitable method. The effect of being informed about the knowhow of the expert at the fifth time did not appear immediately. It can be inferred that, even though the beginner knows the expert's know-how, he does not have sufficient skill to convert it to the actual work movement. In the comments the beginner wrote after the fifth time, he started to mention of the heating power of the burner, the condition of the fire and the handle part for holding the glass tube called ponte. These words are related to the skill in rotating glass tubes and the skill in heating the tubes while rotating them. Therefore, these statements suggest the sign of the beginner becoming aware of the limit of his skill while trying to achieve high-quality bending work through trial and error. The quality of the product the beginner produced at the eighth time can be considered as the state he achieved through his own skill based on the know-how of the expert. It is thought that non-expert imitates only appearance features of expert. On the other hand, the meanings of the motions are clarified by hearing on expert's know-how, and beginner who learned it has a clear the problems and it seems that learning effect which cannot be obtained by simple imitation of experts comes out.

It is possible for viewers to get noticed by using video, and furthermore, it was shown that quality could be improved by adding expert's know-how information in this program. In addition, it is possible to get of know-how of experts by interviewing using process analysis even if the expert cannot realize his know-how. The expert's know-how is difficult to realize in the conventional method of directing experts to beginners, but this self-learning program is considered effective in that know-how is accumulated in companies and its effect can be verified.

\section{CONCLUSION}

In the bending work of quartz glass, we discovered our newly developed self-learning program has the potential in contributing to improve the productivity and the quality of the bending work by beginners. In the past training of the processing skill, only the video of the expert was shown to the beginners and the skill improvement after that was left to the personal effort of each beginner. In this program, the differences in movement were made easier to recognize through the comparison of the movements of beginners themselves and the movement of the expert in video. Hence a potential for passing on the short-time processing that is characteristic to the work of the expert was detected. Moreover, by asking the beginner to write down comments after each production trial, it was made it possible to visualize the thinking of the beginner toward skill improvement, and therefore, aside from the problem recognition of the beginner, enabled the educator and the supervisor to grasp the situation and provide an appropriate support. Such a self-learning program has no previous example in the training of the fire processing of quartz glass, and it is possible to develop it toward other fire processing techniques in future through this study. One can speculate on the possibilities of developing a learning program with function to synchronize the videos of the expert and the test subject in order to heighten the visual effect or with function to automatically feedback the differences from the videos. This study demonstrated the basic effect. This program is expected to be applied in future to the entirely different areas where there exist experts and beginners, such as sports or medical sites.

\section{FUTURE WORK}

It is necessary to investigate the tendency when the number of subjects is increased. However, since there are very few beginners engaged in quartz glass processing, we plan to verify the effect of this program when non-experts with some experience years are taken as subjects.

In addition, it is necessary to add expert knowhow information to enhance the effectiveness of this program. There is a possibility that the glass temperature just before the expert's bending motion is higher than the beginner's. We are planning to shoot thermography video under processing. We think that learning effects of subjects can be further enhanced by subjects watching the difference in processing temperature on video. 


\section{REFERENCES}

[1] J. Brophy, ed. "Using video in teacher education", Emerald Group Publishing Limited, 2003.

[2] J. S. Kounin, "Discipline and group management in classrooms.", 1970

[3] K. Nakahira, M. Akahane, Y. Fukui, "Faculty Development for Playing and Singing Education with Blended Learning”, Japan Journal of Educational Technology, Vol. 34, p. 45-48, 2010

[4] T. Shirasawa, T. Akakura, "Development and evaluation of an elearning system that supports technical skill education in small-to medium-sized manufacturing firms.", Japan Journal of Educational Technology, Vol. 29, No. 4, p. 559-566, 2005

[5] K. Tokunaga, K. Hirano, "e-Learning Based Self-Learning of Nursing Skills by Video Recording and Watching", Transactions of Japanese Society for Information and Systems in Education, Vol. 31, No. 1, p. 8792, 2014

[6] J. Downey, "It's not as easy as it looks: Preservice teachers' insights about teaching emerging from an innovative assignment in educational psychology." Teaching Educational Psychology, Vol. 3.1, p. 1-13, 2008

[7] K. Suetake, "On the Practice of Educational Engineering”, Igaku Kyoiku / Medical Education (Japan), Vol. 4, No. 3, p. 164-171, 1973
[8] S. Tomita, T. Goto, T. Kondoh, T. Suzuki, "The Effective Management Method for the Vocational-Initiation in Order to Train Staffs using Digitalized Manual", Journal of Japan Management Diagnosis Association, Vol. 8, p. 227-232, 2008

[9] H. Umemura, Analysis of the Skills on Bruner Works in Glass Fire Processing, Human Engineering, Vol.47, p. 139-148, 2011

[10] M. Suda, T. Takahashi, A. Hattori, A. Goto, and H. Hamada 、 "Process Analysis of Expert and Non-expert Engineers in Quartz Glass Bending Process", DHM (International Conference on Digital Human Modeling and Applications in Health, Safety, Ergonomics and Risk Management) 2016, LNCS (Lecture Notes in Computer Science) 9745, p. 191-200, 2016

[11] M. Suda, T. Takahashi, A. Hattori, A. Goto, and H. Hamada , "Educational Effect Using Expert Model in Fire Process of Quartz Glass" International Conference on Applied Human Factors and Ergonomics, AHFE 2017: Advances in Human Factors in Training, Education, and Learning Sciences pp 105-112, 2017

[12] Y. Takahashi, R. Kijima, "What are Human Capability, Letting and Growing? -- What We Can Do for Better VR Education System-“", Journal of the Virtual Reality Society of Japan, Vol.16, No.4、 p. 615622,2011 